\title{
QUASILINEAR ELLIPTIC PROBLEMS WITH CRITICAL EXPONENTS AND DISCONTINUOUS NONLINEARITIES
}

\author{
PhuONG LE
}

Abstract. Using a recent fixed point theorem in ordered Banach spaces by S. Carl and S. Heikkilä, we study the existence of weak solutions to nonlinear elliptic problems $-\operatorname{div} a(x, \nabla u)=f(x, u)$ in a bounded domain $\Omega \subset \mathbb{R}^{n}$ with Dirichlet boundary condition. In particular, we prove that for some suitable function $g$, which may be discontinuous, and $\delta$ small enough, the $p$-Laplace equation

$$
-\operatorname{div}\left(|\nabla u|^{p-2} \nabla u\right)=|u|^{p^{*}-2} u+\delta g(x, u)
$$

has a positive solution which goes to 0 as $\delta \rightarrow 0^{+}$, where $p^{*}$ is the critical exponent. Mathematics subject classification (2010): 35J62, 35D30, 47H10.

Keywords and phrases: p-Laplace, critical exponents, discontinuous nonlinearities, positive solutions.

\section{REFERENCES}

[1] C. O. Alves, A. M. Bertone, J. V. Goncalves, A variational approach to discontinuous problems with critical Sobolev exponents, J. Math. Anal. Appl., 265 (2002), 103-127.

[2] M. Badiale, Critical exponent and discontinuous nonlinearities, Differential Integral Equations, 6 (1993), 1173-1185.

[3] M. BAdiale, G. TARANTELlo, Existence and multiplicity results for elliptic problems with critical growth and discontinuous nonlinearities, Nonlinear Anal., Theory Methods Appl., 29 (1997), 639677.

[4] A. Beurling, A. E. Beurling, A theorem on duality mappings in Banach spaces, Ark. Mat., 4 (1961), 405-411.

[5] G. Bonanno, P. CANDito, Non-differentiable functionals and applications to elliptic problems with discontinuous nonlinearities, J. Differ. Equations, 244 (2008), 3031-3059.

[6] S. CARL, S. HEIKKILÄ, Elliptic problems with lack of compactness via a new fixed point theorem, J. Differ. Equations, 186 (2002), 120-140.

[7] S. CARL, S. HEIK KIL ̈̈, Nonlinear Differential Equations In Ordered Spaces, Chapman \& Hall/CRC, London, 2000

[8] S. CARL, S. HEIKKILÄ, Existence and multiplicity for quasilinear elliptic inclusions with nonmonotone discontinuous multifunction, Nonlinear Anal., Real World Appl., 10 (2009), 2326-2334.

[9] H. Chrayteh, J. M. Rakotoson, Eigenvalue problems with fully discontinuous operators and critical exponents, Nonlinear Anal., Theory Methods Appl., 73 (2010), 2036-2055.

[10] S. A. Marano, D. Motreanu, On a three critical points theorem for non-differentiable functions and applications to nonlinear boundary value problems, Nonlinear Anal., Theory Methods Appl., 48 (2002), 37-52.

[11] I. PohozaEv, On the eigenfunctions of the equation $\Delta u+\lambda f(u)=0$, Dokl. Akad. Nauk SSSR, 165 (1965), 36-39.

[12] P. PuCCI, J. SERrin, A general variational identity, Indiana Univ. Math. J., 35 (1986), 681-703.

[13] X. SHANG, Existence and multiplicity of solutions for a discontinuous problems with critical Sobolev exponents, J. Math. Anal. Appl., 385 (2012), 1033-1043.

[14] X. SHANG, Z. WANG, Existence of solutions for discontinous $p(x)$-Laplacain problems with critical exponents, Electronic Journal of Differential Equations, Vol. 2012 (2012), No. 25, pp. 112. 